\title{
Immunohistochemical demonstration of the type III intermediate filament peripherin in human rectal mucosae and well-differentiated endocrine neoplasms
}

\author{
MITSUAKI ISHIDA ${ }^{1}$, RYOJI KUSHIMA ${ }^{2}$, TOKUHIRO CHANO ${ }^{1}$ and HIDETOSHI OKABE ${ }^{1,2}$ \\ ${ }^{1}$ Department of Clinical Laboratory Medicine and ${ }^{2}$ Division of Diagnostic Pathology, \\ Shiga University of Medical Science, Shiga 520-2192, Japan
}

Received March 16, 2007; Accepted May 30, 2007

\begin{abstract}
Peripherin is a type III neuronal intermediate filament and its expression is involved in the growth and development of the peripheral nervous systems. Peripherin expression has been reported in cutaneous endocrine carcinomas, but not in rectal well-differentiated endocrine neoplasms (carcinoid tumors). Well-differentiated endocrine neoplasms have been reported to have a relatively high incidence of metastasis, but there is no complete parameter for prediction of their malignant behavior. The aim of the present study was to clarify the expression of peripherin in human fetal and adult rectal mucosae and rectal welldifferentiated endocrine neoplasms and the significance of peripherin expression in well-differentiated endocrine neoplasms. Expression of peripherin was studied immunohistochemically in 3 fetal hindgut mucosae, 10 non-neoplastic rectal mucosae, 12 rectal well-differentiated endocrine neoplasms without metastases, and 5 well-differentiated endocrine neoplasms with metastases. Adult rectal mucosal epithelial cells did not have peripherin. However, transient expression of peripherin was detected in the subgroup of epithelial cells of the fetal rectum. Peripherin was demonstrated in all of the rectal well-differentiated endocrine neoplasms without metastases (12/12 cases), but was absent from some of the well-differentiated endocrine neoplasms with metastases ( $3 / 5$ cases). Constant expression of peripherin in rectal well-differentiated endocrine neoplasms without metastases (12/12) seems to reflect the phenotype of the subpopulation of epithelial cells confined to the fetal rectum. However, loss of its expression was observed in cases with metastases (3/5) and can be regarded as an additional para-
\end{abstract}

Correspondence to: Dr Hidetoshi Okabe, Department of Clinical Laboratory Medicine and Division of Diagnostic Pathology, Shiga University of Medical Science, Tsukinowa-cho, Seta, Otsu, Shiga 520-2192, Japan

E-mail: okabe@belle.shiga-med.ac.jp

Key words: endocrine neoplasm, carcinoid tumor, metastasis, peripherin, rectum meter to predict the risk of metastasis in rectal welldifferentiated endocrine neoplasms.

\section{Introduction}

Endocrine tumors arising from epithelial tissues usually have several markers common to neurons. However, their manner of neuronal marker expression varies considerably depending on the origin of each tumor. Peripherin is one such neural marker, belonging to the type III intermediate filaments with a molecular weight of $56 \mathrm{kDa}(1)$, encoded on chromosome 12 (2). This intermediate filament is expressed in peripheral nervous systems through a lifetime from their early developmental stage (3-5) and in their neoplastic counterparts (6). It is frequently expressed in cutaneous neuroendocrine carcinomas (Merkel cell carcinomas) (7), but there have been no reports on peripherin expression in rectal endocrine neoplasms and in non-neoplastic rectal mucosae. Herein, we report the presence of peripherin immunoreactivity in fetal and adult rectal mucosal epithelial cells and their neoplasms, and discuss the significance of peripherin expression in rectal endocrine neoplasms in correlation with their metastatic ability.

\section{Materials and methods}

Tissue specimens and clinicopathological features of rectal endocrine neoplasms. The material consisted of 40 formalinfixed and paraffin-embedded tissue specimens of consecutive rectal endocrine neoplasms from 17 patients in our hospital during 2001-2005. All of these cases arose from the rectum although no intentional selection was done, and there were no cases arising from the appendix or any other portion of the colon. The median age of the patients (13 men and 4 women) was 56.6 years (range, 26-82 years). These tumors were diagnosed by at least two pathologists approved by the Japanese Society of Pathology. Rectal well-differentiated endocrine neoplasms were classified into two groups according to the description in the World Health Organization Classification of Tumors, Pathology and Genetics of Tumors of the Digestive System (8), and Histological Typing of Endocrine Tumors (9) as follows. In Group A, a well-differentiated endocrine neoplasm (carcinoid tumor) without metastases is 
defined as a neoplasm of monomorphous endocrine cells showing mild or no atypia and growing in the form of solid nests, trabeculae or pseudoglands, restricted to the mucosa or submucosa without angioinvasion, and having no metastasis to the lymph nodes and other organs, including the liver. In Group B, a well-differentiated endocrine neoplasm (carcinoid tumor) with metastases is defined as a neoplastic lesion composed of endocrine cells showing moderate atypia and growing in the form of solid nests, trabeculae or larger, less well defined cellular aggregates, which deeply invades (muscularis propria or beyond) and shows metastases to lymph nodes or the liver. In this study, the two categories were distinguished by the combination of histological findings and evaluation of metastatic condition by computed tomography (CT) scan and/or magnetic resonance imaging (MRI). Elastica van Gieson staining was performed in addition to hematoxylin and eosin staining for the evaluation of angioinvasion. The tumor size was evaluated by the maximum dimension of the tumor tissue after formalin fixation.

Ten non-neoplastic rectal mucosae attached to the resected colon and colorectal carcinomas and rectal and colon mucosae of three fetuses aborted around 10-11 weeks of gestation were also analyzed.

Immunohistochemistry. Deparaffinized 3- $\mu \mathrm{m}$ sections of the specimens were processed for the LSAB system (Dako Japan Co., Ltd., Kyoto, Japan) using the following primary antibodies: peripherin monoclonal mouse antibody (diluted 1:100; PJM50, Novocastra Laboratories Ltd., Newcastle upon Tyne, UK), serotonin monoclonal mouse antibody (diluted 1:100; 5HT-H209, Dako), Ki-67 monoclonal mouse antibody (diluted 1:50; MM1, Novocastra), synaptophysin monoclonal mouse antibody (diluted 1:200; 27G12, Novocastra), and chromogranin A (diluted 1:50; LK2H10, Novocastra). Antigen retrieval with $20 \mathrm{~min}$ of incubation in a microwave at $500 \mathrm{~W}$ with $0.01 \mathrm{M}$ citrate $(\mathrm{pH}$ 6.0) was performed before the application of the primary antibodies of peripherin, Ki-67, synaptophysin, and chromogranin $\mathrm{A}$, and $15 \mathrm{~min}$ of pronase $(0.05 \%)$ digestion at $37^{\circ} \mathrm{C}$ was performed for anti-serotonin. Then, the sections were washed with $0.1 \mathrm{M}$ phosphatebuffered saline ( $\mathrm{pH}$ 7.4) and bathed in $3 \% \mathrm{H}_{2} \mathrm{O}_{2}$ in methanol for $20 \mathrm{~min}$ at room temperature to quench endogenous peroxidase activity. Subsequently, primary antibodies were applied to the sections, which were then incubated in the humidified chamber at $4^{\circ} \mathrm{C}$ overnight. After three washing steps in phosphate-buffered saline, sections were incubated with biotinylated secondary antibody for $20 \mathrm{~min}$ at room temperature and then sequentially stained using a $0.1 \%$ peroxidase-conjugated streptavidin solution, according to the manufacturer's instructions. Finally, sections were incubated in 3,3'-diaminobenzidine tetrahydrochloride (DAB; Nichirei) for a few minutes and then counterstained with hematoxylin. Immunohistochemical staining of peripherin and other markers was carried out in the serial sections to evaluate the correlation between marker distributions.

Evaluation of immunoreactivity. Immunohistochemical findings were verified by control studies. Negative controls consisted of slides run without the primary antibody. The specificity of the immunoreactivity to individual antibodies was evaluated by the inner and outer positive controls. Nonneoplastic rectal mucosal endocrine cells within the tumor tissue slides were used as the inner controls for the immunoreactivity to serotonin, synaptophysin and chromogranin A and submucosal ganglia was used as a positive control of peripherin. Sections of dorsal root ganglia mounted on the slides were used for the external positive control of peripherin. Lymph node sections were used for the external positive control of Ki-67. Ki-67 labeling indices were evaluated by counting the percentage of positive cells in 1000 tumor cells.

\section{Results}

Fetal and adult non-neoplastic rectal mucosae. At the end of the first trimester, peripherin-positive epithelial cells were scattered in the rectum, including the cloaca (Fig. 1A), but not in the upper portion of the colon. On the other hand, peripherin-positive cells were not detected in non-neoplastic adult rectal mucosae, although peripherin was clearly demonstrated in the submucosal ganglion cells (Fig. 1B).

Well-differentiated endocrine neoplasms without metastases. As described in the section of Materials and methods, our 12 well-differentiated endocrine neoplasms (carcinoid tumors) without metastases were confined to the mucosa and submucosa of the rectal wall (Fig. 2A), without lymphatic and venous invasion; the median tumor size was $3.8 \mathrm{~mm}$ (range, 2-8 mm) (Table I). The tumor Ki-67 labeling indices were $<1 \%$ (Fig. 2B) (Table I).

Synaptophysin was positive in all well-differentiated endocrine neoplasms without metastases (12/12) (Fig. 2C) and chromogranin A was positive in 5 cases (5/12) (Fig. 2D). Serotonin was revealed in 5 cases $(5 / 12)$. Peripherin-positive cells were abundant in all 12 of the well-differentiated endocrine neoplasms without metastases (Fig. 2E) and their distribution was not related to the immunoreactivity to serotonin.

Well-differentiated endocrine neoplasms with metastases. Five cases of well-differentiated endocrine neoplasms (carcinoid tumors) with metastases invaded beyond the muscularis propria (Fig. 3A). Median tumor size was $13.8 \mathrm{~mm}$ (range, 8-22 mm) (Table I), and the tumor Ki-67 labeling indices were $>1 \%$, ranging from 2 to $3 \%$ (Fig. 3B). Synaptophysin was positive in all five of these neoplasms (Fig. 3C) and chromogranin A was positive in 2 of the 5 cases (Fig. 3D). Three cases did not have peripherin immunoreactivity (Table I) (Fig. 3E) and immunohistochemical profiles of individual primary tumors and their metastatic lesions were fundamentally the same. Distribution of peripherin immunoreactivity was not related to the immunoreactivity to serotonin as in the cases without metastases.

\section{Discussion}

Endocrine neoplasms of the gastrointestinal tract have neuroendocrine markers such as synaptophysin, chromogranin A, and neuron-specific enolase in addition to epithelial markers $(10,11)$. Peripherin, a type III neuronal intermediate filament, has not been reported in gastrointestinal mucosae or endocrine neoplasms. 

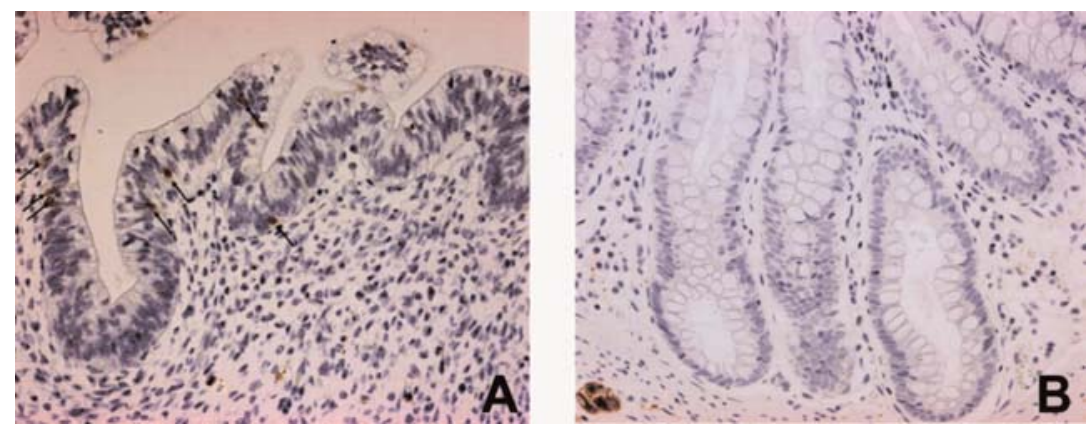

Figure 1. (A) Immunohistochemical staining of peripherin in fetal rectal mucosa (original magnification $\mathrm{x} 200$ ). Peripherin-positive epithelial cells were present in rectal mucosa at the end of the first trimester (arrows). (B) Immunohistochemical staining of peripherin in adult rectal mucosa (original magnification x100). Submucosal ganglion cells were positive for peripherin, but no peripherin-positive epithelial cells were seen in non-neoplastic adult rectal mucosa.
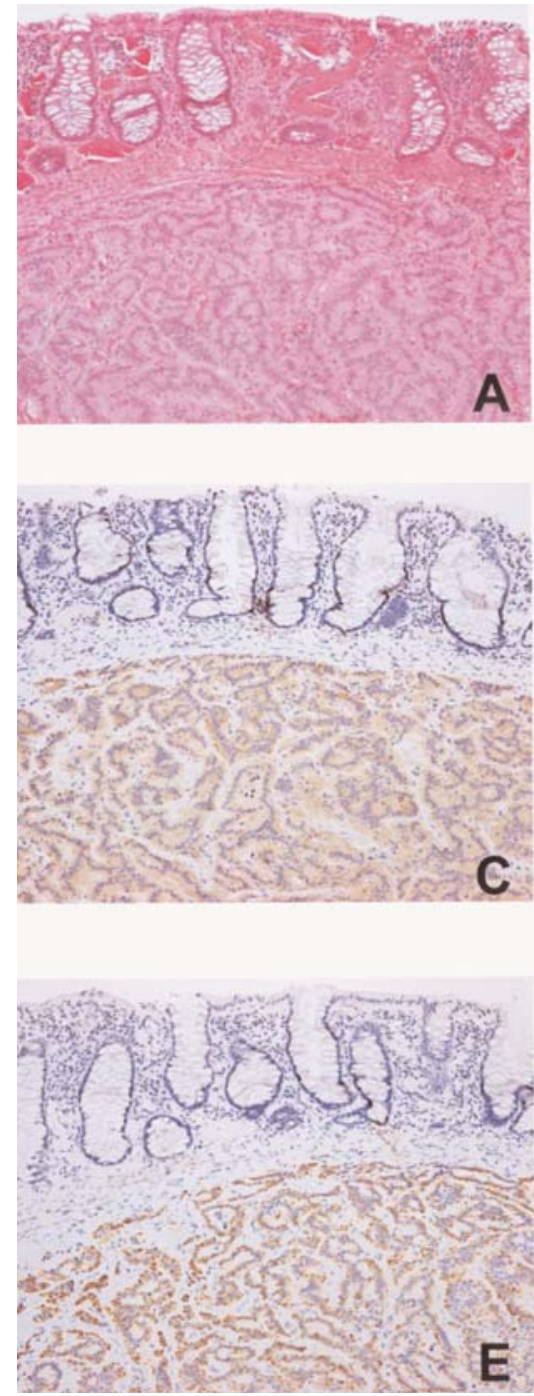
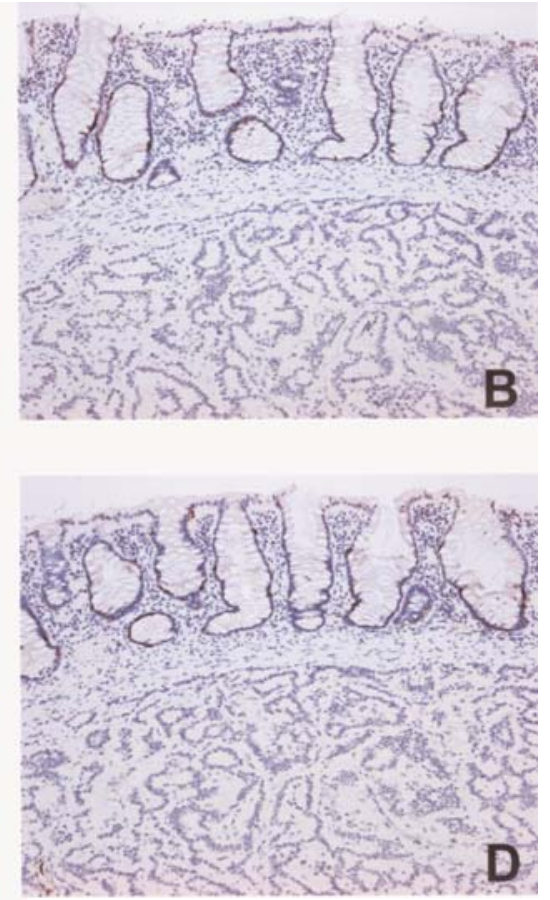

Figure 2. Well-differentiated endocrine neoplasm without metastasis (Case 11) (A) H\&E (original magnification x100). A typical well-differentiated endocrine neoplasm without metastases showed trabecular, insular growth of uniform neuroendocrine cells. (B) Immunohistochemical staining of Ki-67 (original magnification x100). The Ki-67 labeling index was $<1 \%$. (C) Immunohistochemical staining of synaptophysin (original magnification $\mathrm{x} 100$ ). Synaptophysin was detected in the tumor cells. (D) Immunohistochemical staining of chromogranin A (original magnification x100). Tumor cells were negative for chromogranin A. (E) Immunohistochemical staining of peripherin (original magnification x100). Peripherin was detected in most of these tumor cells (E).

tumors in the rectum may be related to the liability of endocrine neoplastic transformation of the subpopulation of stem cells in this area, which transiently express peripherin during their endocrine differentiation. The appendix is the other major site of lower gastrointestinal endocrine neoplasms in Caucasians but not in Japanese, and there was no appendix endocrine neoplasm in our 17 cases. Accordingly,
As shown in our study, fetal rectal epithelial cells are subdivided into two groups based on the immunoreactivity to peripherin: a group with peripherin and a group without peripherin. Constant expression of peripherin in all of our rectal well-differentiated endocrine neoplasms without metastases seems to reflect the fetal phenotype of the former group confined to the rectum. High incidence of endocrine 
Table I. Profiles of rectal well-differentiated endocrine neoplasms and immunoreactivities of peripherin, serotonin and the Ki-67 labeling indices.

\begin{tabular}{|c|c|c|c|c|c|c|}
\hline Specimen no. & $\begin{array}{c}\text { Age (years)/ } \\
\text { Sex }\end{array}$ & Histology & $\begin{array}{l}\text { Size } \\
(\mathrm{mm})\end{array}$ & Peripherin & Serotonin & $\begin{array}{l}\text { Ki-67 labeling } \\
\text { index }(\%)\end{array}$ \\
\hline Case 1 & 43/Male & Well & 4 & + & - & $<1$ \\
\hline Case 2 & 53/Female & Well & 8 & + & - & $<1$ \\
\hline Case 3 & 40/Female & Well & 3 & + & - & $<1$ \\
\hline Case 4 & 53/Female & Well & 2 & + & + & $<1$ \\
\hline Case 5 & 76/Male & Well & 3 & + & - & $<1$ \\
\hline Case 6 & 67/Male & Well & 2 & + & - & $<1$ \\
\hline Case 7 & 55/Male & Well & 5 & + & + & $<1$ \\
\hline Case 8 & 52/Male & Well & 3 & + & - & $<1$ \\
\hline Case 9 & 36/Male & Well & 3 & + & + & $<1$ \\
\hline Case 10 & 54/Male & Well & 5 & + & + & $<1$ \\
\hline Case 11 & 26/Male & Well & 4 & + & + & $<1$ \\
\hline Case 12 & 69/Male & Well & 4 & + & - & $<1$ \\
\hline Case 13 & 67/Male & Well + LN & 11 & - & - & $2-3$ \\
\hline Case 14 & 39/Male & Well + LN & 12 & + & + & $2-3$ \\
\hline Case 15 & 75/Male & Well + liver & 16 & + & - & $2-3$ \\
\hline Case 16 & $82 /$ Female & Well + liver & 22 & - & - & $2-3$ \\
\hline Case 17 & 75/Male & Well + liver & 8 & - & - & $2-3$ \\
\hline
\end{tabular}

Well, well-differentiated endocrine neoplasm (carcinoid tumor) without metastases; Well + LN, well-differentiated endocrine neoplasm (carcinoid tumor) with lymph node metastases; Well + liver, well-differentiated endocrine neoplasm (carcinoid tumor) with liver metastases.
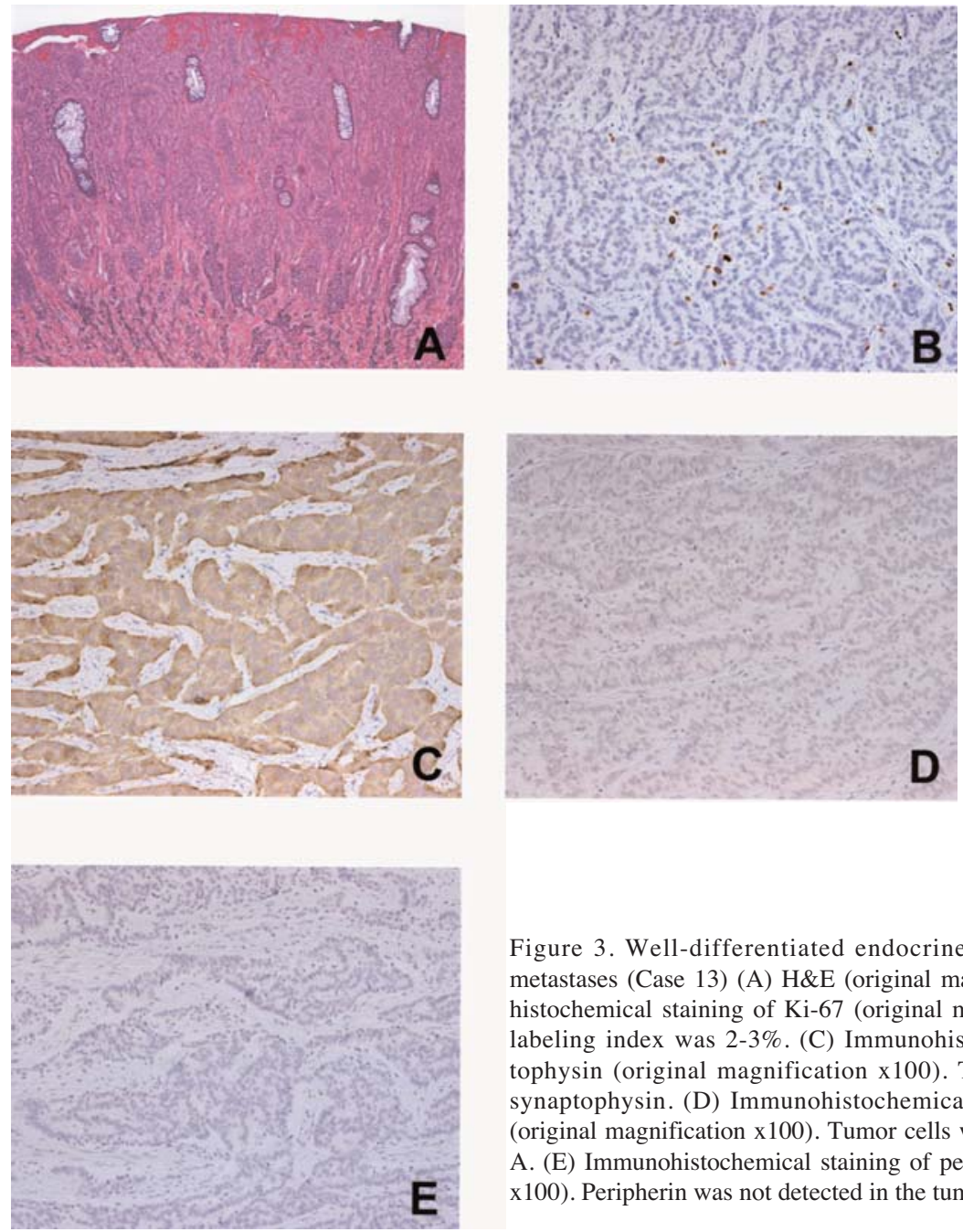

Figure 3. Well-differentiated endocrine neoplasm with lymph node metastases (Case 13) (A) H\&E (original magnification x40). (B) Immunohistochemical staining of Ki-67 (original magnification x100). The Ki-67 labeling index was 2-3\% . (C) Immunohistochemical staining of synaptophysin (original magnification x100). Tumor cells were positive for synaptophysin. (D) Immunohistochemical staining of chromogranin A (original magnification $\mathrm{x} 100$ ). Tumor cells were negative for chromogranin A. (E) Immunohistochemical staining of peripherin (original magnification $\mathrm{x} 100)$. Peripherin was not detected in the tumor cells. 
it is not certain whether peripherin is expressed in appendix endocrine neoplasms, so additional study is required to resolve this question.

Rectal well-differentiated endocrine neoplasms (carcinoid tumors) have a relatively high incidence of lymph node and liver metastases (12-14) and prediction of their metastatic ability is one of the major problems. In the World Health Organization Classification of Tumors, Pathology and Genetics of Tumors of the Digestive Systems (8) and WHO Histological Typing of Endocrine Tumors (9), smaller size $(<20 \mathrm{~mm})$ and low mitotic figures ( $<2$ mitoses per 10 high power fields) or low Ki-67 labeling index $(<1 \%)$ are regarded as indicators of the benign nature of the well-differentiated endocrine neoplasms. However, these indices are still not complete for the prediction of malignant nature in rectal well-differentiated endocrine neoplasms. For example, Soga reported that rectal well-differentiated endocrine neoplasms, restricted to the submucosal growth, exhibited a metastasis rate of $9.7 \%$ in tumors $<10 \mathrm{~mm}, 3.7 \%$ in tumors $<5 \mathrm{~mm}$, and $13.2 \%$ in tumors 5.1-10 mm (14). Other indicators of malignant potential, such as angioinvasion (9), invasion beyond the muscularis propria (8-10), cellular atypia (15), and DNA ploidy (16) are also not always sufficient to separate the cases with metastases from cases without metastases.

Our rectal well-differentiated endocrine neoplasms with metastases were larger than the cases without metastases, but did not always exceed $20 \mathrm{~mm}$. The Ki-67 labeling index was higher than $1 \%$ in all of the metastatic cases. Peripherin was demonstrated in only two of the five cases. Accordingly, loss of peripherin immunoreactivity may have significance for predicting the risk of metastasis in rectal well-differentiated endocrine neoplasms.

\section{Acknowledgements}

The authors wish to thank Mr. Y. Miyahira, Mr. M. Iwai and Ms. Y. Iwata for their technical assistance.

\section{References}

1. Portier MM, De Nechaud B and Gros F: Peripherin, a new member of the intermediate filament protein family. Dev Neurosci 6: 335-345, 1983.

2. Blumenfeld A, Lucente DE, Trofatter JA, et al: Peripherin gene is linked to keratin 18 gene on human chromosome 12 . Somat Cell Mol Genet 21: 83-88, 1995.

3. Escurat M, Djabali K, Gumpel M, Gros F and Portier MM: Differential expression of two neuronal intermediate-filament proteins, peripherin and the low-molecular-mass neurofilament protein (NF-L), during the development of the rat. J Neurosci 10: 764-784, 1990.
4. Thompson MA and Ziff EB: Structure of the gene encoding peripherin, an NGF-regulated neuronal-specific type III intermediate filament protein. Neuron 2: 1040-1053, 1989.

5. Fuchs E and Weber K: Intermediate filaments: structure, dynamics, function and disease. Annu Rev Biochem 63: 345-382, 1994.

6. Pedersen WA, Becker LE and Yeger H: Expression and distribution of peripherin protein in human neuroblastoma cell lines. Int J Cancer 53: 463-470, 1993.

7. Baudoin C, Meneguzzi G, Portier MM, et al: Peripherin, a neuronal intermediated filament protein, is stably expressed by neuroendocrine carcinomas of the skin, their xenograft on nude mice, and the corresponding primary cultures. Cancer Res 53: 1175-1181, 1993

8. Capella C, Solcia E, Sobin LH and Arnold R: Endocrine tumors of the colon and rectum. In: World Health Organization Classification of Tumors, Pathology and Genetics of Tumors of the Digestive Systems. Hamilton SR and Aaltonen LA (eds). IARC Press, Lyon, pp137-139, 2000.

9. Solcia E, Klöppel G and Sobin LH: Endocrine tumors of the gastrointestinal tract. In: Histological Typing of Endocrine Tumors. 2nd edition. Solcia E, Klöppel G and Sobin LH (eds). Springer-Verlag, Berlin, pp61-69, 2000.

10. Federspiel BH, Burke AP, Sobin LH and Shekitka KM: Rectal and colonic carcinoids. A clinicopathological study of 84 cases. Cancer 65: 135-140, 1990.

11. Miettinen M: Synaptophysin and neurofilament proteins as markers for neuroendocrine tumors. Arch Pathol Lab Med 111: 813-818, 1987.

12. Maggard MA, O'Connel JB and Ko CY: Updated populationbased review of carcinoid tumors. Ann Surg 240: 117-122, 2004.

13. Soga J: Carcinoid and their variant endocrinomas. An analysis of 11842 reported cases. J Exp Clin Cancer Res 22: 517-530, 2003.

14. Soga J: Early-stage carcinoids of the gastrointestinal tract: an analysis of 1914 reported cases. Cancer 103: 1587-1595, 2005.

15. Koura AN, Giacco GG, Curley SA, Skibber JM, Feig BW and Ellis LM: Carcinoid tumors of the rectum: effect of size, histopathology, and surgical treatment on metastasis-free survival. Cancer 79: 1294-1298, 1997.

16. Tsioulias G, Muto T, Kubota Y, et al: DNA ploidy pattern in rectal carcinoid tumors. Dis Colon Rectum 34: 31-36, 1991 